\title{
Aggressive surgical resection of a metastatic leiomyosarcoma, a case report and brief review of literature
}

\author{
Kian Bagheri, Afsheen Moshtaghi and Ara S Klijian* \\ Department of Thoracic Surgery, Sharp/Scripps Hospitals, San Diego, California, USA
}

\begin{abstract}
Objective: To present a case report of a patient with leiomyosarcoma (LMS) with pulmonary metastases.

Study design: Case report.

Results: A 64-year-old male presenting with primary sarcoma arising from the right thigh. Progression of disease resulted in metastatic pulmonary lesions bilaterally. Diagnosis of LMS was confirmed on PET/CT and histology. Patient differed chemotherapy and immediately underwent video-assisted thoracic surgery (VATS) resection of both lesions over the course of one month.

Conclusion: Given the aggressive nature of primary LMS arising from the extremity's timely resection of metastatic pulmonary lesions is warranted. Use of chemotherapy could worsen survival outcomes and delay surgical treatment. Use of VATS allows surgical resection of multiple recurrent lesions in a manner that allows for repeat interventions in a short period of time.
\end{abstract}

\section{Introduction}

Sarcomas can develop from any primary site, with those arising from the extremities having worse prognosis compared to those of the viscera or retroperitoneum [1,2]. As a result, primary extremity sarcomas have an increased likelihood of pulmonary metastasis [3,4]. Yet those with leiomyosarcoma (LMS) have an improved prognosis compared to other sarcoma variants $[5,6]$.

LMS compose $5 \%$ to $10 \%$ of soft tissue sarcomas [7]. Of those with distant metastatic LMS 25\% have pulmonary involvement making it the most common site $[6,8]$. In this context, we present a case report of a patient with metastatic LMS with pulmonary involvement and identify key features and treatment modalities that could benefit future patients.

\section{Case report}

Patient is a 64-year-old male who presents with metastatic leiomyosarcoma to the lungs bilaterally. Patient originally presented one year prior to presentation with a $5-\mathrm{cm}$ right thigh lesion which was observed several months prior but slowly getting larger. Subsequent biopsy was suggestive of sarcoma (Figure 1). He subsequently underwent excision of the lesion which diagnosed sarcoma with negative margins. Initial PET scan demonstrated no metastasis, thus was consistent with stage II leiomyosarcoma. At the time, he declined adjuvant chemotherapy and proceeded with radiation therapy only.

After one year, surveillance PET/ CT scan demonstrated two bilateral pulmonary masses (Figure 2a, 2b). The lesion involving the right lower lobe measured $4.9 \times 3.5 \mathrm{~cm}$ while the one involving the left lower lobe measured $5.5 \times 7.5 \mathrm{~cm}$. These findings prompted referral to thoracic surgery for possible resection.

Immediately after consultation, patient underwent a right thoracoscopy with resection of tumor with resection and reconstruction

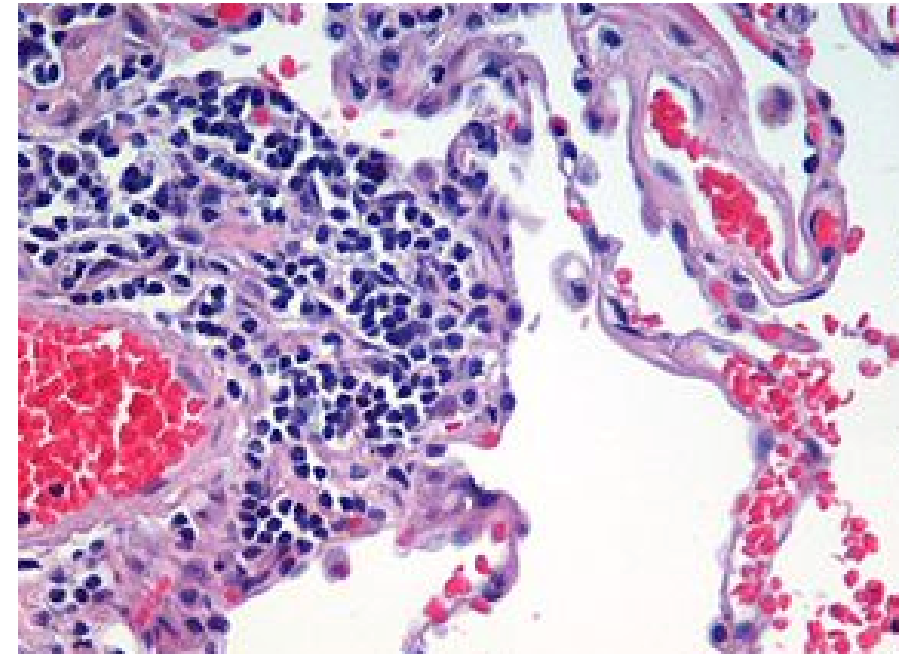

Figure 1. Hematoxylin and eosin stain of right thigh lesion suggestive of leiomyosarcoma

of the chest wall and diaphragm where the tumor was attached. Patient was subsequently discharged home on post-operative day two.

Four weeks later, patient underwent left thoracoscopy with tumor resection including attachment points to pericardium, diaphragm and chest wall. Similarly, patient was discharged on postop day two.

${ }^{\star}$ Correspondence to: Ara S Klijian, Director, Cardiovascular \& Thoracic Surgical Institute of San Diego, Attending Cardiothoracic Surgeon, Department of Thoracic Surgery, Sharp/Scripps Hospitals, 3131 Berger Avenue, Suite 250, San Diego, CA 92123, USA, E-mail: klijian@hotmail.com

Key words: metastatic leiomyosarcoma, thoracoscopy, thoracotomy, VATS

Received: June 12, 2018; Accepted: June 19, 2018; Published: June 22, 2018 


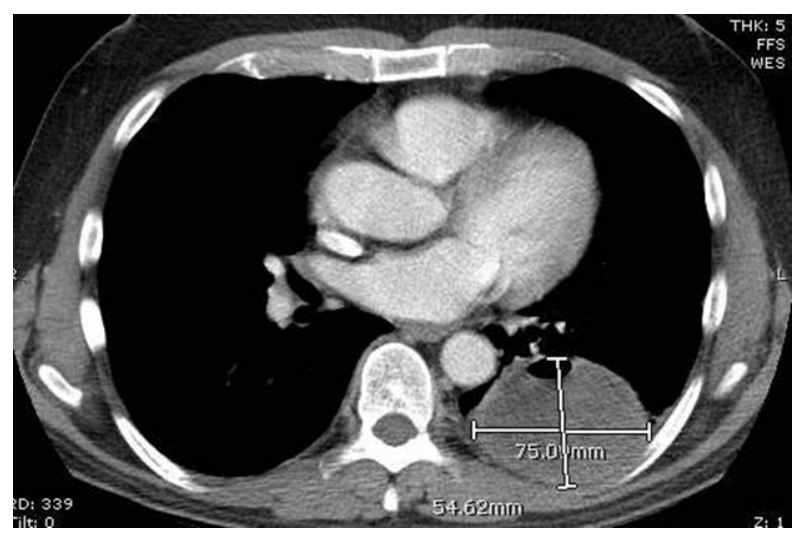

Figure 2a. Left lower lobe metastatic mass

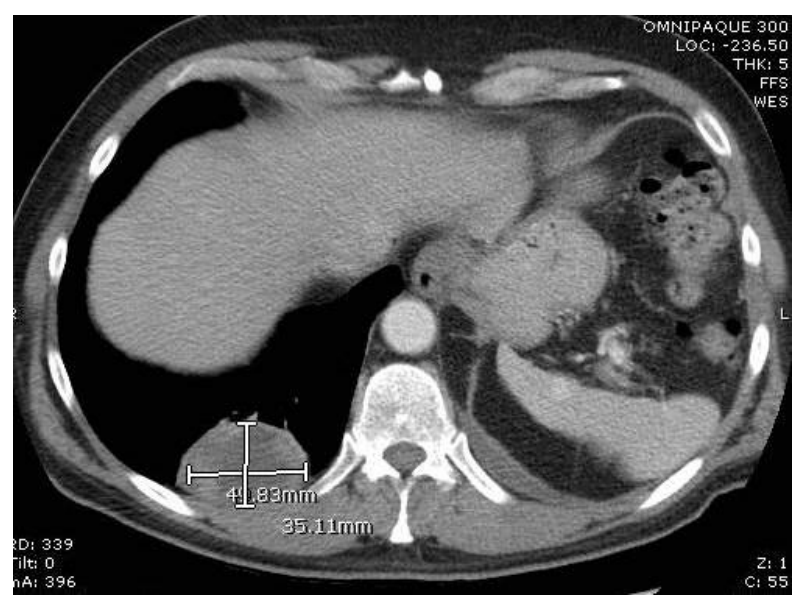

Figure 2b. Right lower lobe metastatic mass

Nine months post-operative PET CT of the chest shows no evidence of recurrence in our patient who remains active. His Pre-op PFT and Post-op PFT has remained stable.

\section{Discussion}

The aggressive nature of LMS demonstrates how quickly metastases can grow within lung parenchyma. Although no current consensus exists to date, surgical excision followed by adjuvant chemotherapy is currently thought to be most effective [9]. Never the less, pre-and post-operative chemotherapy was differed by the patient. Literature demonstrates no clear benefit to those who received neoadjuvant or adjacent therapy $[10,11]$.

In those with metastatic LMS and pulmonary infiltrates, multivariate analysis shows metastasectomy significantly improved overall survival. Interestingly, combined surgical and chemotherapy regiments did not improve patient outcomes [8]. This has resulted in the encouraging 5 -year survival outcomes of $38 \%$ to $52 \%$ for those who undergo LMS pulmonary metastasectomy $[5,12,13]$. Given these findings, our case report highlights the importance of aggressive wide surgical excision for improved survival outcomes.

Yet despite surgical resection, LMS is non-curable and the patient will ultimately succumb to secondary pulmonary recurrence. Evidence shows those who undergo repeat resection of pulmonary lesions can extend survival [14]. Like us, others have adopted the approach of aggressive secondary and tertiary metastasectomy with up to a $36 \%$ survival rates $[14,15]$. With this in mind, decrease time to surgical resection as has been shown to be the most important predictor of survival [5]. Thus, we suggest resection should never be delayed for chemotherapy.

Instrumental to serial resection is the use of video-assisted thoracic surgery (VATS) which has established nearly equivalent outcomes to open approaches and associated with shorter hospital stays [16]. The utility of VATS is clearly demonstrated in this case report. This approach provided a means to complete two sequential pulmonary resections over a span of four weeks' time. Because of the minimally invasive approach the patient was discharged on post-operative day two with no inpatient complications both times.

\section{Conclusion}

In patients presenting with bilateral metastatic pulmonary LMS, aggressive surgical resection is warranted. Delaying treatment for chemotherapy could compromise survival outcomes.

\section{References}

1. Gadd MA, Casper ES, Woodruff JM, McCormack PM, Brennan MF (1993) Development and treatment of pulmonary metastases in adult patients with extremity soft tissue sarcoma. Ann Surg 218: 705-712. [Crossref]

2. Hoekstra H, Meyer S, Bruggink E, Blankensteijn J (1994) Repeated resection of recurrent pulmonary metastatic soft tissue sarcoma. Europe PMC 20: 436-440.

3. Vezeridis MP, Moore R, Karakousis CP (1983) Metastatic patterns in soft-tissue sarcomas. Arch Surg 118: 915-918. [Crossref]

4. Brennan MF (1989) Management of extremity soft-tissue sarcoma. Am J Surg 158 71-78. [Crossref]

5. Burt BM, Ocejo S, Mery CM, Dasilva M, Bueno R, et al. (2011) Repeated and aggressive pulmonary resections for leiomyosarcoma metastases extends survival. Ann Thorac Surg 92: 1202-1207. [Crossref]

6. Billingsley KG, Burt ME, Jara E, Ginsberg RJ, Woodruff JM, et al. (1999) Pulmonary metastases from soft tissue sarcoma: analysis of patterns of disease and postmetastasis survival. Ann Surg 229: 602. [Crossref]

7. Van Glabbeke M, van Oosterom AT, Oosterhuis JW, Mouridsen H, Crowther D, et al (1999) Prognostic factors for the outcome of chemotherapy in advanced soft tissue sarcoma: an analysis of 2,185 patients treated with anthracycline-containing first-line regimens - a European Organization for Research and Treatment of Cancer Soft Tissue and Bone Sarcoma Group Study. J Clin Oncol 17: 150-150. [Crossref]

8. Penel N1, Italiano A, Isambert N, Bompas E, Bousquet G, et al. (2009) Factors affecting the outcome of patients with metastatic leiomyosarcoma treated with doxorubicincontaining chemotherapy. Ann Oncol 21: 1361-1365. [Crossref]

9. Weitz Jr, Antonescu CR, Brennan MF (2003) Localized extremity soft tissue sarcoma: improved knowledge with unchanged survival over time. J Clin Oncol 21: 2719-2725. [Crossref]

10. Lanza LA, Putnam JB, Benjamin RS, Roth JA (1991) Response to chemotherapy does not predict survival after resection of sarcomatous pulmonary metastases. Ann Thorac Surg 51: 219-224. [Crossref]

11. Porter GA, Cantor SB, Walsh GL, Rusch VW, Leung DH, et al. (2004) Costeffectiveness of pulmonary resection and systemic chemotherapy in the management of metastatic soft tissue sarcoma: a combined analysis from the University of Texas MD Anderson and Memorial Sloan-Kettering Cancer Centers. $J$ Thorac Cardiovasc Surg 127: 1366-1372. [Crossref]

12. Blackmon SH, Shah N, Roth JA, Correa AM, Vaporciyan AA, et al. (2009) Resection of pulmonary and extrapulmonary sarcomatous metastases is associated with long-term survival. Ann Thorac Surg 88: 877-884. [Crossref]

13. Anraku M, Yokoi K, Nakagawa K, Fujisawa T, Nakajima J, et al. (2004) Pulmonary metastases from uterine malignancies: results of surgical resection in 133 patients. $J$ Thorac Cardiovasc Surg 127: 1107-1112.

14. Rizzoni WE, Pass HI, Wesley MN, Rosenberg SA, Roth JA (1986) Resection of recurrent pulmonary metastases in patients with soft-tissue sarcomas. Arch Surg 121 1248-1252. [Crossref] 
Bagheri K (2018) Aggressive surgical resection of a metastatic leiomyosarcoma, a case report and brief review of literature

15. Weiser MR, Downey RJ, Leung DH, Brennan MF (2000) Repeat resection of pulmonary metastases in patients with soft-tissue sarcoma. J Am Coll Surg 191: 184190. [Crossref]
16. Gossot D, Radu C, Girard P, Le Cesne A, Bonvalot S, et al. (2009) Resection of pulmonary metastases from sarcoma: can some patients benefit from a less invasive approach? Ann Thorac Surg 87: 238-243. [Crossref]

Copyright: (C2018 Bagheri K. This is an open-access article distributed under the terms of the Creative Commons Attribution License, which permits unrestricted use, distribution, and reproduction in any medium, provided the original author and source are credited. 